\title{
HOW THE ISTHMUS OF PANAMA ALLOWED HOMO TO EVOLVE
}

STANLEY, Steven M., Morton K. Blaustein Dept. of Earth \& Planetary Sciences, Johns Hopkins Univ., Baltimore, MD 21218, U.S.A.

The evolutionary stability of Australopithecus for about $1.5 \mathrm{~m} . \mathrm{y}$. before it gave rise to Homo can be explained by this animal's semi-arboreal life, which was necessary for avoiding predators in the absence of advanced weapons and fire. This mode of life (1) locked its postcranial anatomy in an adaptive compromise between terrestrial and arboreal requirements and (2) precluded the evolution of the brain of Homo because climbing mothers could not have carried the helpless neonates that accompanied the delayed development that produces the expanded brain of Homo. Analyses of body, brain, and birth weights indicate that Australopithecus matured like an ape, whereas Homo rudolfensis experienced a delay like that of Homo sapiens.

The transition to Homo coincided with the onset of the modern ice age in the Northern Hemisphere, when climates became more arid in Africa and grassy habitats expanded at the expense of forests. Shrinkage of woodlands caused the extinction of Australopithecus but permitted the evolution of Homo from one population that was forced to abandon habitual climbing but was fortunate enough to survive the crisis. This transition within the human family paralleled that for antelopes, in which taxa adapted to forests died out and taxa adapted to grassy terrain diversified.

The onset of the most recent ice age can be traced causally to the uplift of the Isthmus of Panama slightly before 3Ma. To account for this ice age, one must explain why the polar region cooled dramatically: because the cool condition persists even during glacial minima, such as the present, it must be the cause, rather than a result, of the the presence of glaciers. The high heat capacity of water dictates that we look to refrigeration of the Arctic Ocean to explain the cooling slightly before 3Ma. What keeps this polar ocean cold today is the transoceanic conveyor belt, which joins the Gulf Stream and descends north of Iceland, looping back to the south and depriving the Arctic Ocean of Atlantic warmth. The primary driving force of this system is the descent, which occurs only because the conveyor belt waters of the Atlantic are more saline than average seawater (Pacific waters are just as cold in the Bering Sea region, but fail to descend because they are less saline). The dry trade winds account for the conveyor belt's high salinity, carrying moisture from its surface waters across Central America to the Pacific. Before the uplift of the Isthmus of Panama, much of the saline Atlantic water would have flowed into the Pacific. This condition, combined with compensatory flow at depth, would have more-or-less balanced the salinities of the North Atlantic and North Pacific oceans; in the absence of its primary driving force, the conveyor belt as we know it would not have existed. The wind-driven Gulf Stream would nonetheless have operated, and some of its water would have entered and warmed the Arctic Ocean, circling westward within it under the influence of the earth's rotation. The uplift of the Isthmus of Panama would have set the modern conveyor belt in motion, isolating the Arctic Ocean and cooling the polar region. A variety of paleoceanographic data substantiates this inferred pattern of change. Most notably, oxygen isotopic ratios rose toward modern values to the east of Panama between 4 and 3 million years ago, reflecting an increase in salinity where the conveyor belt now flows through the Caribbean.

The implication of this chain of causation is that the human genus would not exist but for the tectonic uplift of a narrow neck of land between the Americas that set in motion a series of changes in oceans and climates that cascaded around the world. 